\title{
Novel length variant of the polypyrimidine tract within the splice acceptor site in intron 8 of the CFTR gene: consequences for genetic testing using standard assays
}

European Journal of Human Genetics (2005) 13, 136-138. doi:10.1038/sj.ejhg.5201261

Published online 24 November 2004

Isolated congenital bilateral absence of the vas deferens (CBAVD) has been considered as an incomplete form of cystic fibrosis (CF), supported by the identification of mutations in the CF transmembrane conductance regulator (CFTR) gene in the majority of these patients. ${ }^{1-4}$ An intron splice variant, called IVS8-5T, is frequently observed in CBAVD $(12.8-43.7 \%){ }^{5-9}$ The splice variant is localized at the splice acceptor site of intron 8 and alternative length variants consist of seven (IVS8-7T) or nine (IVS8-9T) thymidines. The IVS8-5T variant is associated with high levels of exon 9 skipping, which result in the production of a nonfunctional CFTR protein. ${ }^{10-12}$ However, the splicing efficiency of the IVS8-5T allele shows interindividual variability, suggesting that it is a CBAVD mutation with incomplete penetrance. Recent studies demonstrated that, in addition to the effect of the Tn tract, exon 9 skipping is also influenced by the (TG)m repeat that precedes the Tn tract. ${ }^{13,14}$

Owing to this, determination of poly-T status is becoming established as a routine assay in infertility cases where CBAVD is suspected. Several methods have been developed. These are usually based on a preliminary PCR amplification of exon 9 and its intronic boundaries with specific primers located in introns flanking exon 9 and subsequent evaluation of the PCR product. Several different techniques to analyse the PCR product have been published including allele-specific oligonucleotide (ASO) hybridization by oligonucleotidic probes that recognize the presence of 5, 7 or 9 thymidines, nested PCR followed by XmnI restriction and nondenaturing gradient gel electrophoresis, linear denaturing gradient gel electrophoresis or capillary zone electrophoresis combined with laser-induced fluoresence detection..$^{3,5,15-17}$ In addition to these widely used methods, a number of less common methods for the characterization of the Tn tract, based on allele-specific PCR assays or radioactive single-strand conformation polymorphism analysis have also been described. ${ }^{18}$ Recently, different commercially available kits (such as ELUCIGENE CF-Poly-T, Tepnel diagnostics, UK;
INNO-LiPA CFTR, Innogenetics, Belgium; Cystic fibrosis v3 5/7/9T OLA ASR, Abbott diagnostics, USA) have been developed to provide laboratories with a simple and accurate means of routinely genotyping the poly-T alleles (5T, 7T and 9T). However, these methods assume that only three length variants of the poly-Tn tract exist in the general population.

During the analysis of exon 9 and adjacent intron sequences by denaturing gradient gel electrophoresis (DGGE) in CBAVD patients pursuing fertility treatment by intracytoplasmic sperm injection, we identified an atypical DGGE pattern. ${ }^{16}$ Direct sequencing of the PCR product showed that the CBAVD patient was a compound heterozygote for the IVS8-9T allele and a novel allele, named IVS8-6T (Figure 1). The IVS8-6T allele is adjacent to a long TG tract (13TG). Recently, the IVS8-5T international study group showed that IVS8-5T alleles adjacent to long TG tracts are substantially more likely to be associated with an abnormal phenotype than IVS8-5T alleles adjacent to short TG tracts. ${ }^{14,19}$ The association between TG tract length and disease penetrance is consistent with the pathogenicity of this new 13TG-6T allele in our CBAVD patient, which also presents the F508del mutation found on a 10TG-9T background. This novel allele was not found in 300 CBAVD or CF patients analysed by nested primers followed by XmnI restriction and ethidium bromide visualization after nondenaturing polyacrylamide gel electrophoresis as previously described by Chillon et al. ${ }^{5}$

Despite the fact that this novel IVS8-6T allele appears to be rare in CBAVD patients, our finding has implications for the identification of pathogenic variants in the Tn tract. Use of allele-specific oligonucleotide hybridization, reverse hybridization or PCR with specific primers for the 5T, 7T or 9T alleles results in the failure of molecular genetic diagnosis, due to an inability to detect other variants than the 5, 7 and 9T alleles. For the other methods used, tests should be performed to determine the ability to distinguish the IVS8-6T allele from the other similar frequently 

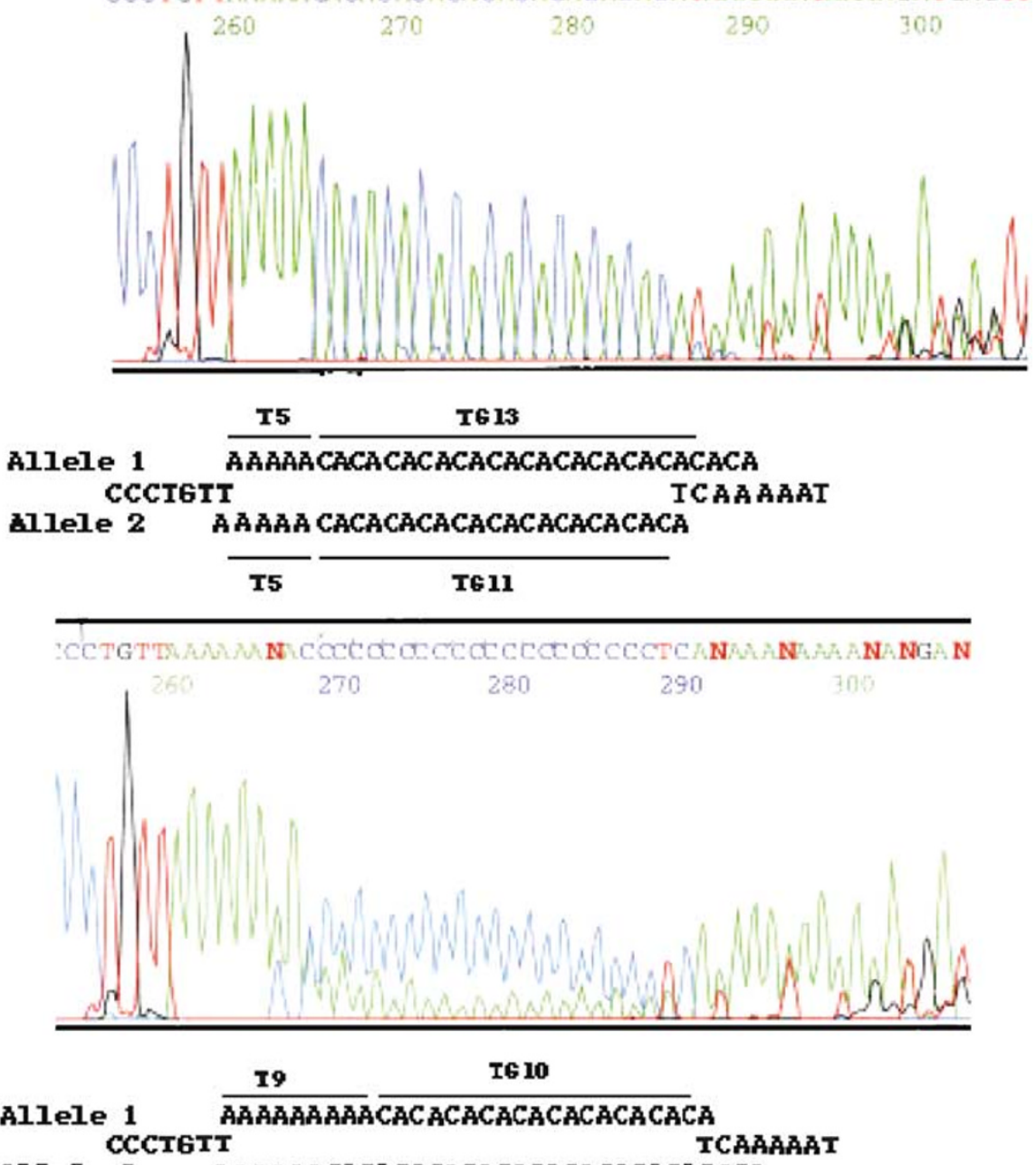

Allele 2 AAAAAACACACACACACACACACACACAC ACA

T6

T613

Figure 1 Automated sequence traces showing the novel IVS8-6T allele at the branch/acceptor site of intron 8 of the CFTR gene. The upper strand sequence was obtained for a (TG)m heterozygous and Tn homozygous subject (genotype: 13TG-5T/ 11TG-5T). The lower strand sequence was obtained for the CBAVD patient with the IVS8-6T variant (genotype: (10TG-9T/ 13TG-6T). A reverse primer was used.

identified alleles (IVS8-5T and IVS8-7T) to avoid a false report of homozygosity for the 5,7 or $9 \mathrm{~T}$ alleles. The existence of novel Tn alleles (such as 3T previously described in CF and in CBAVD, and and 6T this study) and the role of the TG stretch in the pathogenic penetrance of a 5T allele suggest that when a diagnostic laboratory wants to perform intron 8 analysis for confirmation of diagnosis of CBAVD, direct sequence analysis of intron 8 appears to be the only logical option. ${ }^{20,21}$

\section{Acknowledgements}

This work was supported by AP-HP hôpitaux de Paris and by a grant from Vaincre La Mucoviscidose.
Marion Viel ${ }^{1}$, Chrystel Leroy ${ }^{1}$, Marie Des Georges ${ }^{2}$, Mireille Claustres $^{2}$ and Thierry Bienvenu*,1

${ }^{1}$ Laboratoire de Biochimie et Génétique Moléculaire, Hôpital Cochin, Paris, France;

${ }^{2}$ Laboratoire de Génétique Moléculaire, Institut Universitaire de Recherche Clinique, 641 avenue du doyen Gaston Giraud, Montpellier Cedex 5, France

*Correspondence: Assistant Professor T Bienvenu. Laboratoire de Biochimie et Génétique Moléculaire, Hôpital Cochin, 123 boulevard de Port-Royal, 75014 Paris, France. Tel: (33) (0)1 44 4124 79; Fax : (33) (0)1 584115 80;

E-mail: bienvenu@cochin.inserm.fr 


\section{References}

1 Anguiano A, Oates RD, Amos JA et al: Congenital bilateral absence of the vas deferens. A primarily genital form of cystic fibrosis. JAMA 1992; 267: 1794-1797.

2 Casals T, Bassas L, Ruiz-Romero J et al: Extensive analysis of 40 infertile patients with congenital absence of the vas deferens: in $50 \%$ of cases only one CFTR allele could be detected. Hum Genet 1995; 95: 205-211.

3 Costes B, Girodon E, Ghanem N et al: Frequent occurrence of the CFTR intron 8 (TG)n 5T allele in men with congenital bilateral absence of the vas deferens. Eur J Hum Genet 1995; 3: 285-293.

4 Culard JF, Desgeorges M, Costa P et al: Analysis of the whole CFTR coding regions and splice junctions in azoospermic men with congenital bilateral aplasia of epididymis or vas deferens. Hum Genet 1994; 93: 467-470.

5 Chillon M, Casals T, Mercier B et al: Mutations in the cystic fibrosis gene in patients with congenital absence of the vas deferens. N Engl J Med 1995; 332: 1475-1480.

6 Dork T, Dworniczak B, Aulehla-Scholz C et al: Distinct spectrum of CFTR gene mutations in congenital absence of vas deferens. Hum Genet 1997; 100: 365-377.

7 Jarvi K, Zielenski J, Wilschanski $\mathrm{M}$ et al: Cystic fibrosis transmembrane conductance regulator and obstructive azoospermia. Lancet 1995; 345: 1578.

8 Lissens W, Mahmoud KZ, El-Gindi E et al: Molecular analysis of the cystic fibrosis gene reveals a high frequency of the intron 8 splice variant $5 \mathrm{~T}$ in Egyptian males with congenital bilateral absence of the vas deferens. Mol Hum Reprod 1999; 5: 10-13.

9 Claustres M, Guittard C, Bozon D et al: Spectrum of CFTR mutations in cystic fibrosis and in congenital absence of the vas deferens in France. Hum Mutat 2000; 16: 143-156.

10 Chu CS, Trapnell BC, Curristin S, Cutting GR, Crystal RG: Genetic basis of variable exon 9 skipping in cystic fibrosis transmembrane conductance regulator mRNA. Nat Genet 1993; 3: 151-156.

11 Chu CS, Trapnell BC, Murtagh Jr JJ et al: Variable deletion of exon 9 coding sequences in cystic fibrosis transmembrane conductance regulator gene mRNA transcripts in normal bronchial epithelium. EMBO J 1991; 10: 1355-1363.

12 Strong TV, Wilkinson DJ, Mansoura MK et al: Expression of an abundant alternatively spliced form of the cystic fibrosis

transmembrane conductance regulator (CFTR) gene is not associated with a cAMP-activated chloride conductance. Hum Mol Genet 1993; 2: 225-230.

13 Cuppens H, Lin W, Jaspers $M$ et al: Polyvariant mutant cystic fibrosis transmembrane conductance regulator genes. The polymorphic (Tg)m locus explains the partial penetrance of the T5 polymorphism as a disease mutation. J Clin Invest 1998; 101: 487-496.

14 Groman JD, Hefferon TW, Casals T et al: Variation in a repeat sequence determines whether a common variant of the cystic fibrosis transmembrane conductance regulator gene is pathogenic or benign. Am J Hum Genet 2004; 74: 176-179.

15 Kiesewetter S, Macek Jr M, Davis C et al: A mutation in CFTR produces different phenotypes depending on chromosomal background. Nat Genet 1993; 5: 274-278.

16 Cazeneuve C, Beldjord C, Kaplan JC, Bienvenu T: Diagnostic usefulness of the polymorphism of the GT dinucleotide and the polythymidine tract in intron 8 of the cystic fibrosis transmembrane conductance regulator (CFTR) gene. Ann Genet 1995; 38: 202-205.

17 Gelfi C, Perego M, Righetti PG et al: Rapid capillary zone electrophoresis in isoelectric histidine buffer: high resolution of the poly-T tract allelic variants in intron 8 of the CFTR gene. Clin Chem 1998; 44: 906-913.

18 Friedman KJ, Heim RA, Knowles MR, Silverman LM: Rapid characterization of the variable length polythymidine tract in the cystic fibrosis (CFTR) gene: association of the 5T allele with selected CFTR mutations and its incidence in atypical sinopulmonary disease. Hum Mutat 1997; 10: 108-115.

19 Shrimpton AE: R117H and IVS8-5T cystic fibrosis mutation detection by restriction enzyme digestion. Mol Diagn 2000; 5: $235-238$.

20 Disset A, Michot C, Guittard C et al: Identification of a T3 allele in a CBAVD (congenital bilateral absence of vas deferens) patient: in vitro studies demonstrate tissue specificity of aberrant exon 9 splicing.; 26th European Cystic Fibrosis Conference, Belfast 4-7 June, 2003.

21 Buratti E, Dork T, Zuccato E, Pagani F, Romano M, Baralle FE: Nuclear factor TDP-43 and SR proteins in vitro and in vivo CFTR exon 9 skipping. EMBO J 2001; 20: 1774-1784. 